\title{
Inhibitor of Apoptosis (IAP) proteins as drug targets for the treatment of cancer David L Vaux
}

Address: Department of Biochemistry, La Trobe University, Plenty Road, Bundoora 3086 Victoria, Australia

Email: d.vaux@latrobe.edu.au

Fl000 Biology Reports 2009, I:79 (doi:10.3410/BI-79)

The electronic version of this article is the complete one and can be found at: http://FI000.com/Reports/Biology/content/I/79

\begin{abstract}
Three companies, Genentech, Aegera Therapeutics/Human Genome Sciences, and Novartis, have commenced phase I clinical trials of inhibitor of apoptosis (IAP) antagonist 'Smac mimetic' compounds for the treatment of cancer. These trials represent the culmination of a line of research that commenced with analysis of how insect viruses stop host cells from killing themselves and led to the discovery of a family of proteins that regulate development in insects and signalling by tumour necrosis factor superfamily members in mammals, which prompted development of drugs that mimic natural IAP-binding proteins to promote cell death.
\end{abstract}

\section{Introduction and context}

Inhibitor of apoptosis (IAP) proteins were identified by Lois Miller and colleagues [1] in a screen for baculoviral genes that could prevent apoptosis of insect cells infected with a virus in which the caspase-inhibitory gene $p 35$ was mutated. Analysis of the sequence of this IAP showed that it bore two domains, termed baculoviral IAP repeats (BIRs), and a carboxy-terminal RING domain. In mammals, four proteins that have one or more BIR domains and a carboxy-terminal RING domain have been identified, namely cellular IAP 1 (CIAP1)/BIRC2, CIAP2/BIRC3, X-linked IAP protein (XIAP)/BIRC4, and melanoma IAP protein (ML-IAP)/BIRC7 [2] (Figure 1).

Increased expression of these IAPs has been observed in many types of cancer. For example, the locus encompassing CIAP1 and CIAP2 is amplified in hepatocellular carcinomas, high levels of XIAP have been reported in cervical cancers, and ML-IAP levels are high in melanoma. In addition, cIAP2 is involved in translocations seen in MALT (mucosa-associated lymphoid tissue) lymphomas. Associations such as these suggest that IAPs might be oncogenic, and if so, targeting them pharmaceutically might be therapeutic [3].
Clues to the identification of natural IAP antagonists came from studying IAPs in Drosophila, which has two BIR-containing proteins with carboxy-terminal RING domains: Drosophila IAP protein 1 (DIAP1) and DIAP2 [4]. Deletion of DIAP1 leads to massive inappropriate cell death during development, resulting in embryonal lethality. Mutations in DIAP1 also enhanced cell death caused by overexpression of the small pro-apoptotic protein Reaper [5]. Subsequently, it was shown that Reaper and proteins encoded by three closely linked genes, grim, hid, and sickle, bound directly to the second BIR of DIAP1 and blocked its anti-apoptotic function [6].

Mammalian IAP-binding proteins were identified by mass spectrometric analysis of proteins co-immunoprecipitating with IAPs from cell lysates $[7,8]$. These mitochondrial proteins, including Smac/Diablo and HtrA2/Omi, bore processed amino-termini similar to the amino-termini of Reaper, Grim, HID, and Sickle [9]. Crystallisation of a Smac-BIR3 of XIAP complex [10] showed that the key interaction was between the four conserved amino-terminal amino acids of the IAPbinding protein with a hydrophobic pocket on the surface of the BIR. 
Figure I. Cellular inhibitor of apoptosis I (cIAPI) and cIAP2 have three baculoviral inhibitor of apoptosis repeat (BIR) domains

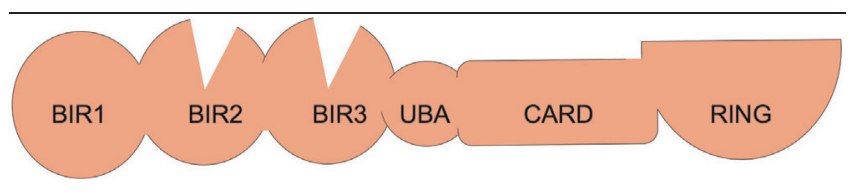

BIRI binds to tumour necrosis factor receptor-associated factor I (TRAFI) and TRAF2; BIR2 and BIR3 bind to Smac/Diablo and IAP antagonist compounds (IACs). The BIRs are followed by a ubiquitin-associated (UBA) domain that allows binding to ubiquitin [33]. This is followed by a caspase recruitment domain (CARD), but no proteins that bind to the CARD of IAPs have been identified. At the carboxy-terminus is a RING domain that allows dimerisation and confers ubiquitin E3 ligase activity.

Peptido-mimetic IAP-antagonist compounds (IACs) that resemble the amino-termini of the IAP-binding proteins have been designed to allow pharmacological antagonism of IAPs. Experiments using these compounds have revealed that they cause apoptosis by modifying tumour necrosis factor (TNF) signalling pathways [11-14].

Despite its name, TNF is only very rarely able to cause cell death on its own and must be combined with inhibitors of transcription or translation, such as actinomycin D or cycloheximide. This implied activity of certain 'survival' genes prevented death of cells treated with TNF alone. Observations that cells lacking the nuclear factor-kappaB (NF- $\kappa$ B) component p65/RelA were susceptible to TNF alone suggested that the survival genes were driven by NF- $\kappa B$ [15].

\section{Major recent advances}

The first connection between IAPs and TNF signalling pathways came with the identification of cIAP1 and cIAP2 in a complex with TNF receptor-associated factor 1 (TRAF1) and TRAF2 that bound to the cytoplasmic domain of TNF receptor 2 (TNFR2) [16]. Subsequently, it was shown that BIR1 of CIAP1 allows it to bind to the TRAFs $[17,18]$.

More recently, it was found that mouse embryonic fibroblasts (MEFs) mutant for cIAP1 could be killed by TNF alone, just like p65/RelA mutant MEFs [12]. This, and experiments in which TNF activation of NF- $\kappa B$ was studied in cells depleted of cIAP1, cIAP2, or both [19,20], revealed that cIAPs are needed for TNF to activate p65/ RelA NF-kB.

Remarkably, addition of an IAC to cells causes cIAP1 to be ubiquitylated and degraded in under half an hour [11-14] (Figure 2). In some cells, XIAP also disappears, but it usually takes longer and might sometimes be due to cleavage by caspases rather than by the proteasome. By
Figure 2. Inhibitor of apoptosis antagonist compounds (IACs) trigger dimerization-dependent autoubiquitylation and degradation of inhibitors of apoptosis (IAPs)

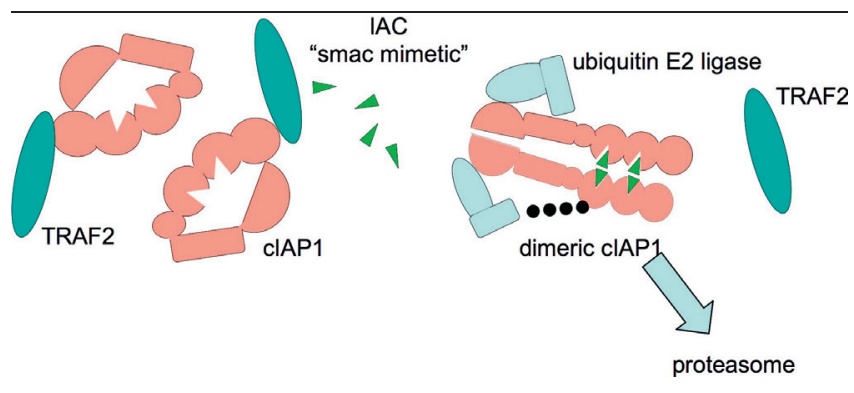

When an IAC 'Smac-mimetic' (green triangles) is added to cells, it binds to baculoviral inhibitor of apoptosis repeat 2 (BIR2) and BIR3 of cellular IAP I (cIAPI). This somehow allows RING dimerisation of cIAPI, which becomes ubiquitylated (black dots) and degraded by the proteasome. Tumour necrosis factor receptor-associated factor 2 (TRAF2) levels are unaffected by addition of IACs.

depleting cells of cIAP1 and cIAP2, IACs have cast a new light on what these IAPs actually do.

TNF alone can kill cIAP1 mutant MEFs and MEFs pretreated with IACs but does not kill XIAP mutant MEFs [12]. This suggests that, in the TNF-triggered death pathway, the targets of IACs are the cIAPs rather than XIAP, and because XIAP is the only IAP that directly inhibits caspase activity [21], it means that IACs do not kill purely by relieving caspase inhibition. Even so, antagonism of XIAP might be important for blocking other death pathways as cIAP-selective antagonists are less potent in promoting apoptosis than pan-selective compounds [22], and sensitisation to other death receptor ligands might require inhibition of XIAP in certain types of cells [23].

Cell lines that are killed by IACs produce autocrine TNF, and blocking TNF receptors prevents the cells from dying. But IACs also sensitise cells to the addition of death receptor ligands such as TNF, Fas ligand, or TNFrelated apoptosis-inducing ligand (TRAIL). This implies that one of the normal functions of cIAPs is to prevent or reduce activation of caspase 8 in response to death ligands (Figure 3).

MEFs treated with IACs, or those in which genes for CIAP1 or TRAF2 are deleted, have constitutively elevated levels of NF- $\kappa B$-inducing kinase (NIK) $[11,12]$, and activation of the downstream non-canonical NF- $k \mathrm{~B}$

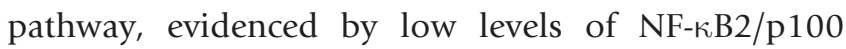
relative to its product NF- $\kappa$ B2/p52 (Figure 4). Activation of this transcription factor pathway might explain the autocrine production of TNF in some cell types. The 
Figure 3. Signalling in response to tumour necrosis factor (TNF) is regulated by inhibitors of apoptosis (IAPs)

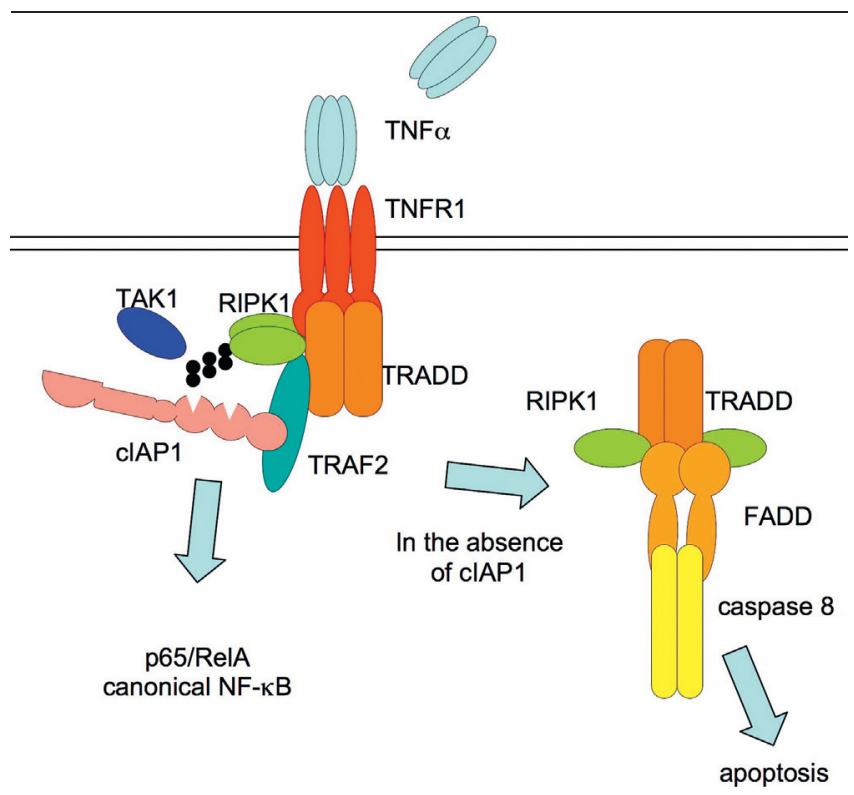

When TNF binds to TNF receptor I (TNFRI), it stimulates formation of a complex containing TRADD (TNFR superfamily IA-associated via death domain), RIPKI (receptor-interacting serine-threonine kinase I), TRAF2 (TNFR-associated factor 2), cIAPI (cellular IAP I), and other proteins. RIPKI becomes $\mathrm{K} 63$ ubiquitylated, inhibitor of kappa-B is phosphorylated and degraded, and the canonical nuclear factor-kappa-B (NF-kB) component p65/RelA is released and enters the nucleus. If cIAPI is removed (by gene deletion or addition of an inhibitor of apoptosis antagonist compound), TNF triggers formation of a second complex containing TRADD, FADD (Fas-associated protein with death domain), RIPKI, and caspase 8, which become activated, leading to apoptosis. TAKI, transforming growth factor (TGF)-beta activated kinase I.

activation of NIK when cIAPs are depleted suggests that a normal role for cIAPs and TRAFs is to channel NF- $\mathrm{B}$ signalling toward the p65/RelA pathway and away from the NIK-activated pathway. For example, when cIAP1 is genetically deleted, phosphorylation and activation of p65/RelA in response to TNF are greatly reduced and delayed, whereas NIK levels are elevated, even in the absence of cytokine stimulation (Figure 4).

So how is TNF able to activate E3 activity of cIAP1 and cIAP2? Like XIAP, CIAP1 and CIAP2 bear carboxyterminal RING domains, which allow them to act as ubiquitin ligases [24]. IAPs can hetero- and homodimerise via their RINGs, which seems to activate them, allowing them to associate with an E2 and leading to their auto-ubiquitylation and degradation by the proteasome [25] (Figure 2). Although it is clear that binding of an IAC to the BIR of an IAP results in activation of its RING, exactly how they do so it not known as the
Figure 4. In the absence of tumour necrosis factor (TNF), cellular inhibitor of apoptosis I (cIAPI) constitutively suppresses nuclear factor-kappa-B (NF-kB)-inducing kinase (NIK) abundance

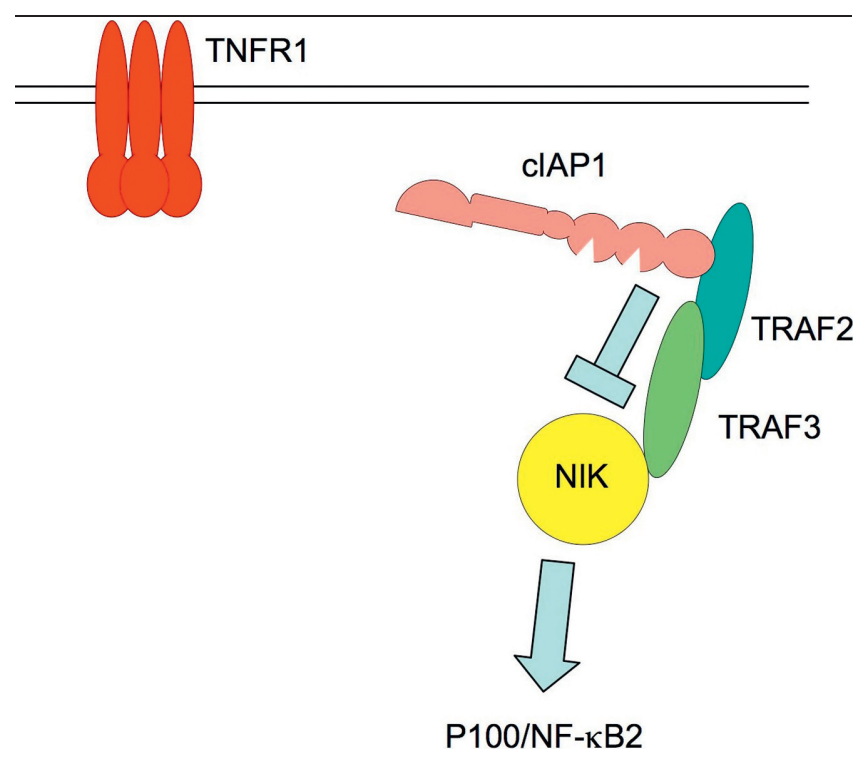

In cells that have not been exposed to cytokines, a complex containing cIAPI, TNF receptor-associated factor 2 (TRAF2), and TRAF3 interacts with NIK, causing it to be ubiquitilated and degraded, so that steady-state levels of NIK are very low. When cIAPI is depleted by addition of an IAP antagonist compound or when genes for CIAPI or TRAF2 are deleted, NIK levels rise, leading to cleavage and activation of the non-canonical NF- $k B$ member pI00/NF- $\kappa$ B2 by generation of the active product, $\mathrm{p} 52$. TNFRI, TNF receptor I.

three-dimensional structure of a whole IAP has not yet been determined.

Mutation of residues at the very end of a cIAP1's RING greatly increases its half-life, but these mutants lose antiapoptotic activity. This suggests that CIAP1 must dimerise at their RINGs in order to activate, and then they ubiquitylate themselves and other associated proteins, such as receptor-interacting serine/threonine kinase 1 (RIPK1) $[19,20,26,27]$, caspases [28], or Smac/Diablo [18]. It is possible that, when cells are exposed to IACs, the IAPs autoubiquitylate and destroy themselves, so they are no longer able to ubiquitylate their physiological targets. This prevents p65/RelA from being activated, while NIK is stabilised, causing processing and activation of p100/NF$\kappa \mathrm{B} 2$ signalling and autocrine production of TNF.

When IACs were given to mice bearing xenograft tumours, the malignant cells were killed, apparently without stimulation of a TNF cytokine storm causing severe side effects $[11,13]$. This was encouragement enough to commence phase I trials in humans, but as yet, no results from Genentech, Inc. (South San Francisco, CA, USA), 
Aegera Therapeutics Inc. (Montreal, QC, Canada)/Human Genome Sciences (Rockville, MD, USA), or Novartis (Basel, Switzerland) have been reported.

\section{Future directions}

Many puzzles remain to be solved in the lab: How does binding of an IAC to the BIR lead to activation of the E3 ligase? What are the direct substrates of IAP E3 activity [RIPK1, RIPK2, Smac/Diablo, ASK1 (apoptosis signalregulating kinase 1$)$, and caspases are among the reported substrates] [26,29-32]? Are these proteins modified by K48, K63, or linear linked ubiquitin? When cIAPs are doing their 'day job' of reducing NIK levels, do they have to be activated by a BIR-binding protein, and if so, what is it? What is the effect of deletion of both cIAP1 and cIAP2? What are the differences between CIAP1 and CIAP2, and what is the role of the caspase recruitment domains and ubiquitin-associated domains in these proteins? We will have to wait and see, just as we will for the clinical trials, which will reveal whether IACs will be therapeutically useful, either as a single agent or in combination with TRAIL or conventional chemotherapy.

\begin{abstract}
Abbreviations
ASK1, apoptosis signal-regulating kinase 1; BIR, baculoviral inhibitor of apoptosis repeat; CIAP, cellular inhibitor of apoptosis; DIAP, Drosophila inhibitor of apoptosis; HID, head involution defective; HtrA2, high temperature requirement $\mathrm{A} 2$; $\mathrm{IAC}$, inhibitor of apoptosis antagonist compound; IAP, inhibitor of apoptosis; MALT, mucosaassociated lymphoid tissue; MEF, mouse embryonic fibroblast; ML-IAP, melanoma inhibitor or apoptosis; NF- $\kappa B$, nuclear factor-kappa-B; NIK, nuclear factor-kappaB-inducing kinase; RIPK1, receptor (TNFRSF)-interacting serine-threonine kinase 1; Smac, second mitochondriaderived activator of caspase; TNF, tumour necrosis factor; TNFR, TNF receptor, TNFRSF, TNFR superfamily; TRAF, TNFR-associated factor; TRAIL, TNF-related apoptosisinducing ligand; XIAP, X-linked inhibitor of apoptosis.
\end{abstract}

\section{Competing interests}

The author is on the Scientific Advisory Board of TetraLogic Pharmaceuticals (Malvern, PA, USA).

\section{Acknowledgements}

The author is funded by the National Health and Medical Research Council and a Center Grant from the Leukemia \& Lymphoma Society.

\section{References}

I. Crook NE, Clem RJ, Miller LK: An apoptosis inhibiting baculovirus gene with a zinc finger like motif. J Virol 1993, 67:2168-74

2. Salvesen GS, Duckett CS: IAP proteins: blocking the road to death's door. Nat Rev Mol Cell Biol 2002, 3:40I-IO.
3. LaCasse EC, Mahoney DJ, Cheung HH, Plenchette S, Baird S, Korneluk RG: IAP-targeted therapies for cancer. Oncogene 2008, 27:6252-75

4. Hay BA, Wassarman DA, Rubin GM: Drosophila homologs of baculovirus inhibitor of apoptosis proteins function to block cell death. Cell I995, 83:1253-62.

5. White K, Grether ME, Abrams JM, Young L, Farrell K, Steller H: Genetic control of programmed cell death in Drosophila. Science 1994, 264:677-83.

6. Vucic D, Kaiser WJ, Harvey AJ, Miller LK: Inhibition of reaper-induced apoptosis by interaction with inhibitor of apoptosis proteins (IAPs). Proc Natl Acad Sci U S A 1997, 94: $10183-8$.

7. Verhagen AM, Ekert PG, Pakusch M, Silke J, Connolly LM, Reid GE, Moritz RL, Simpson RJ, Vaux DL: Identification of DIABLO, a mammalian protein that promotes apoptosis by binding to and antagonizing IAP proteins. Cell 2000, I02:43-53.

FI000 Factor 6.0 Must Read

Evaluated by Alun M Davies 03 Dec 2001

8. Du CY, Fang M, Li YC, Li L, Wang XD: Smac, a mitochondrial protein that promotes cytochrome c-dependent caspase activation by eliminating IAP inhibition. Cell 2000, 102:33-42.

FI000 Factor 6 Must Read

Evaluated by Alun M Davies 03 Dec 2001

9. Silke J, Verhagen AM, Ekert PG, Vaux DL: Sequence as well as functional similarity for DIABLO/Smac and Grim, Reaper and Hid? Cell Death Differ 2000, 7:1275.

10. Wu G, Chai JJ, Suber TL, Wu JW, Du CY, Wang XD, Shi YG: Structural basis of IAP recognition by Smac/DIABLO. Nature 2000, 408: $1008-12$.

II. Varfolomeev E, Blankenship JW, Wayson SM, Fedorova AV, Kayagaki N, Garg P, Zobel K, Dynek JN, Elliott LO, Wallweber HJ, Flygare JA, Fairbrother WJ, Deshayes K, Dixit VM, Vucic D: IAP antagonists induce autoubiquitination of c-IAPs, NF-kappaB activation, and TNFalpha-dependent apoptosis. Cell 2007, |31:669-8|.

FI000 Factor 4.8 Must Read

Evaluated by David Wallach 2I Dec 2007, Shiv Pillai 26 Feb 2008

12. Vince JE, Wong WW, Khan N, Feltham R, Chau D, Ahmed AU, Benetatos CA, Chunduru SK, Condon SM, McKinlay M, Brink R, Leverkus M, Tergaonkar V, Schneider P, Callus BA, Koentgen F, Vaux DL, Silke J: IAP antagonists target cIAPI to induce TNFalpha-dependent apoptosis. Cell 2007, 131:682-93.

FI000 Factor 3.0 Recommended

Evaluated by David Wallach 2I Dec 2007

13. Gaither A, Porter D, Yao Y, Borawski J, Yang G, Donovan J, Sage D, Slisz J, Tran M, Straub C, Ramsey T, lourgenko V, Huang A, Chen Y, Schlegel R, Labow M, Fawell S, Sellers WR, Zawel L: A Smac mimetic rescue screen reveals roles for inhibitor of apoptosis proteins in tumor necrosis factor-alpha signaling. Cancer Res 2007, 67: || 493-8.

14. Petersen SL, Wang L, Yalcin-Chin A, Li L, Peyton M, Minna J, Harran P. Wang $X$ : Autocrine TNFalpha signaling renders human cancer cells susceptible to Smac-mimetic-induced apoptosis. Cancer Cell 2007, I 2:445-56.

15. Wang CY, Mayo MW, Baldwin AS: TNF- and cancer therapyinduced apoptosis: potentiation by inhibition of NF-kappaB. Science 1996, 274:784-7.

16. Rothe M, Pan MG, Henzel WJ, Ayres TM, Goeddel DV: The TNFR2TRAF signaling complex contains two novel proteins related to baculoviral inhibitor of apoptosis proteins. Cell 1995, 83: 1243-52.

17. Varfolomeev E, Wayson SM, Dixit VM, Fairbrother WJ, Vucic D: The inhibitor of apoptosis protein fusion c-IAP2.MALTI stimulates NF-kappaB activation independently of TRAFI AND TRAF2. J Biol Chem 2006, 28I:29022-9. 
18. Samuel T, Welsh K, Lober T, Togo SH, Zapata JM, Reed JC: Distinct BIR domains of cIAPI mediate binding to and ubiquitination of tumor necrosis factor receptor-associated factor 2 and second mitochondrial activator of caspases. J Biol Chem 2006, 28I: 1080-90.

19. Mahoney DJ, Cheung HH, Mrad RL, Plenchette S, Simard C, Enwere E, Arora V, Mak TW, Lacasse EC, Waring J, Korneluk RG: Both cIAPI and cIAP2 regulate TNFalpha-mediated NF-kappaB activation. Proc Natl Acad Sci U S A 2008, 105:I 1778-83.

FI000 Factor 3.0 Recommended

Evaluated by Kristina Vuori 25 Sep 2008

20. Varfolomeev E, Goncharov T, Fedorova AV, Dynek JN, Zobel K, Deshayes K, Fairbrother W], Vucic D: c-IAP I and c-IAP2 are critical mediators of tumor necrosis factor alpha (TNFalpha)-induced NF-kappaB activation. J Biol Chem 2008, 283:24295-9.

21. Eckelman BP, Salvesen GS, Scott FL: Human inhibitor of apoptosis proteins: why XIAP is the black sheep of the family. EMBO Rep 2006, 7:988-94.

22. Ndubaku C, Varfolomeev E, Wang L, Zobel K, Lau K, Elliott LO, Maurer B, Fedorova AV, Dynek JN, Koehler M, Hymowitz SG, Tsui V, Deshayes K, Fairbrother WJ, Flygare JA, Vucic D: Antagonism of cIAP and XIAP proteins is required for efficient induction of cell death by small-molecule IAP antagonists. ACS Chem Biol 2009, 4:557-66.

23. Jost PJ, Grabow S, Gray D, McKenzie MD, Nachbur U, Huang DC, Bouillet $P$, Thomas HE, Borner C, Silke J, Strasser A, Kaufmann T: XIAP discriminates between type I and type II FAS-induced apoptosis. Nature 2009, 460:1035-9.

FI000 Factor 6.0 Must Read

Evaluated by Andreas Villunger 16 Sep 2009

24. Silke J, Kratina T, Chu D, Ekert PG, Day CL, Pakusch M, Huang DC, Vaux DL: Determination of cell survival by RING-mediated regulation of inhibitor of apoptosis (IAP) protein abundance. Proc Natl Acad Sci U S A 2005, 102:16182-7.

25. Mace PD, Linke K, Feltham R, Schumacher FR, Smith CA, Vaux DL, Silke J, Day CL: Structures of the cIAP2 RING domain reveal conformational changes associated with ubiquitin-conjugating enzyme (E2) recruitment. J Biol Chem 2008, 283:3 I633-40.
26. Bertrand MJ, Milutinovic S, Dickson KM, Ho WC, Boudreault A, Durkin J, Gillard JW, Jaquith JB, Morris SJ, Barker PA: cIAPI and cIAP2 facilitate cancer cell survival by functioning as E3 ligases that promote RIPI ubiquitination. Mol Cell 2008, 30:689-700.

FI000 Factor 6.0 Must Read

Evaluated by Hao Wu Ol Oct 2008

27. Wang L, Du F, Wang X: TNF-alpha induces two distinct caspase-8 activation pathways. Cell 2008, 133:693-703.

28. Huang HK, Joazeiro CAP, Bonfoco E, Kamada S, Leverson JD, Hunter T: The inhibitor of apoptosis, cIAP2, functions as a ubiquitin-protein ligase and promotes in vitro monoubiquitination of caspases 3 and 7. Biol Chem 2000, 275:2666 I-4.

29. Bertrand MJ, Doiron K, Labbe K, Korneluk RG, Barker PA, Saleh M: Cellular inhibitors of apoptosis CIAPI and CIAP2 are required for innate immunity signaling by the pattern recognition receptors NODI and NOD2. Immunity 2009, 30:789-80I.

FI000 Factor 3.0 Recommended

Evaluated by Neal Silverman 12 June 2009

30. Choi YE, Butterworth M, Malladi S, Duckett CS, Cohen GM, Bratton SB: The E3 ubiquitin ligase cIAPI binds and ubiquitinates caspase- 3 and -7 via unique mechanisms at distinct steps in their processing. J Biol Chem 2009, 284:12772-82.

31. Hu S, Yang $X$ : Cellular inhibitor of apoptosis $I$ and 2 are ubiquitin ligases for the apoptosis inducer Smac/DIABLO. J Biol Chem 2003, 278:10055-60.

32. Zhao Y, Conze DB, Hanover JA, Ashwell JD: Tumor necrosis factor receptor 2 signaling induces selective c-IAPI-dependent ASK I ubiquitination and terminates mitogen-activated protein kinase signaling. J Biol Chem 2007, 282:7777-82.

33. Gyrd-Hansen M, Darding M, Miasari M, Santoro MM, Zender L, Xue W, Tenev T, da Fonseca PC, Zvelebil M, Bujnicki JM, Lowe S, Silke J, Meier P: IAPs contain an evolutionarily conserved ubiquitin-binding domain that regulates NF-kappaB as well as cell survival and oncogenesis. Nat Cell Biol 2008, 10:1309-17. 